Received:September 1, 2021 Accepted: September 23, 2021

First published online: September 25, 2021

${ }^{*}$ Corresponding authors S. Oh

Phone: +82-2-910-5732 Fax: +82-2-910-5739

E-mail: ohsa@kookmin.ac.kr G.Y. Song

Phone: +82-42-821-5926

Fax: +82-42-823-6566

E-mail: gysong@cnu.ac.kr

${ }^{\dagger}$ These authors contributed equally to this work.

Supplementary data for this paper are available on-line only at http://jmb.or.kr.

pISSN 1017-7825 eISSN 1738-8872

Copyright $(\subset 2021$ by the authors. Licensee KMB. This article is an open access article distributed under the terms and conditions of the Creative Commons Attribution (CC BY) license.

\section{Root Bark of Morus alba L. and Its Bioactive Ingredient, Ursolic Acid, Suppress the Proliferation of Multiple Myeloma Cells by Inhibiting Wnt/ $\beta$-Catenin Pathway}

\author{
Geu Rim Song ${ }^{1,4 \dagger}$, Yoon Jung Choi ${ }^{2 \dagger}$, Soo Jin Park ${ }^{3}$, Subeen Shin ${ }^{1,4}$, Giseong Lee ${ }^{5}$, Hui Ji Choi ${ }^{2}$, \\ Do Yup Lee ${ }^{3}$, Gyu-Yong Song ${ }^{2 *}$, and Sangtaek Oh ${ }^{1,4 *}$ \\ ${ }^{1}$ Department of Bio and Fermentation Convergence Technology, Kookmin University, Seoul 02707, Republic of Korea \\ ${ }^{2}$ College of Pharmacy, Chungnam National University, Daejeon 34134, Republic of Korea \\ ${ }^{3}$ Department of Agricultural Biotechnology, Center for Food and Bioconvergence, Research Institute for \\ Agricultural and Life Sciences, Seoul National University, Seoul 08826, Republic of Korea \\ ${ }^{4}$ Department of Interdisciplinary Program for Bio-Health Convergence, Kookmin University, Seoul 02707, Republic \\ of Korea \\ ${ }^{5}$ College of General Education, Kookmin University, Seoul 02707, Republic of Korea
}

\begin{abstract}
The root bark of Morus alba L. has cytotoxic activity against several types of cancer cells. However, little is known about its chemopreventive mechanisms and bioactive metabolites. In this study, we showed that $M$. alba L. root bark extracts (MRBE) suppressed $\beta$-catenin response transcription (CRT), which is aberrantly activated in various cancers, by promoting the degradation of $\beta$-catenin. In addition, MRBE repressed the expression of the $\beta$-catenin/T-cell factor (TCF)-dependent genes, cmyc and cyclin D1, thus inhibiting the proliferation of RPMI-8226 multiple myeloma (MM) cells. MRBE induced apoptosis in MM cells, as evidenced by the increase in the population of annexin VFITC-positive cells and caspase-3/7 activity. We identified ursolic acid in MRBE through LC/mass spectrum (MS) and observed that it also decreased intracellular $\beta$-catenin, c-myc, and cyclin D1 levels. Furthermore, it suppressed the proliferation of RPMI-8226 cells by stimulating cell cycle arrest and apoptosis. These findings suggest that MRBE and its active ingredient, ursolic acid, exert antiproliferative activity by promoting the degradation of $\beta$-catenin and may have significant chemopreventive potential against MM.
\end{abstract}

Keywords: Morus alba L., Wnt/ $\beta$-catenin signaling, multiple myeloma, ursolic acid

\section{Introduction}

Multiple myeloma (MM), a malignant plasma cell neoplasm, is the second most frequent hematological malignancy, comprising $10-15 \%$ of all blood cancers [1]. Well-established MM characteristics include the infiltration and clonal expansion of plasma cells within the bone marrow and the excessive accumulation of serum immunoglobulin [2]. Because MM is not currently curable, developing new therapeutics based on the underlying molecular mechanisms altered in these cancer cells is urgently needed.

The excessive accumulation of $\beta$-catenin and the subsequent upregulation of $\beta$-catenin response transcription (CRT) contribute to the development and progression of several cancers [3]. In MM, the Wnt/ $\beta$-catenin pathway is constitutively activated, and the intracellular $\beta$-catenin levels are elevated [4]. $\beta$-catenin translocates to the nucleus, where it forms a complex with T-cell factor (TCF)/lymphocyte enhancer factor family transcription factors (LEF). This complex activates the expression of target genes that play essential roles in tumor development, including c-myc, cyclin D1, metalloproteinase-7, and peroxisome proliferator-activated receptor- $\delta$ [5-8]. Therefore, accelerating $\beta$-catenin turnover may be an effective strategy for chemoprevention and treatment of MM.

The root bark of Morus alba L. has been used in herbal medicine because of its anti-inflammatory, liverprotective, kidney-protective, hypotensive, diuretic, anti-cough, and analgesic effects [9]. Recently, M. alba L. root bark extracts (MRBE) were shown to have anticancer activity $[10,11]$ and suppress the migration of human nonsmall-cell lung cancer cells [12]. However, the molecular mechanisms behind this potential anticancer activity and the active ingredients responsible have not been elucidated. In this study, we found that MRBE inhibit CRTpositive cancer cell proliferation by inhibiting the Wnt/ $\beta$-catenin pathway. We also identified ursolic acid as the bioactive ingredient underlying this activity. 
Materials and Methods

Preparation of $M$. alba L. Root Bark Extract

The dried root barks of M. alba L. ( $1 \mathrm{~kg}$ ) were extracted with $80 \%$ (v/v) ethanol (3 L) under reflux 3 times for $2 \mathrm{~h}$. After the liquid was filtered, the fluid was concentrated under vacuum to obtain the extracts $(9.7 \mathrm{~g})$.

\section{Cell Cultures, Reporter Assays, and Chemicals}

RPMI8226, HEK293, and Wnt3a-L cells were purchased from the American Type Culture Collection and cultured in RPMI1640 (RPMI8226 and MM.1S) and Dulbecco's modified Eagle's media (HEK293 and Wnt3a-L) supplemented with $10 \%$ fetal bovine serum, $120 \mu \mathrm{g} / \mathrm{ml}$ penicillin, and $200 \mu \mathrm{g} / \mathrm{ml}$ streptomycin. HEK293-FL (TOPFlash) reporter cells were established as previously described [13]. Wnt3a-CM was prepared as previously described [14]. Luciferase assays were conducted using the Dual-Luciferase Assay Kit (Promega, USA), following the manufacturer's instructions. Lithium chloride (LiCl), MG-132, and ursolic acid were purchased from SigmaAldrich (USA).

\section{Western Blot Assays}

Cytosolic fractions were obtained as previously described [15]. Whole-cell fractions were prepared in RIPA buffer. We used the Bradford assay for protein quantization. Proteins $(30 \mu \mathrm{g})$ were separated by SDS-PAGE in 4$12 \%$ gradient gels (Invitrogen, USA) and transferred to nitrocellulose membranes (Bio-Rad Laboratories, USA). The membranes were soaked in SuperBlock Blocking Buffer (Thermo Scientific) for $1 \mathrm{~h}$ at room temperature and then incubated overnight with primary antibodies. The following primary antibodies were used: anti- $\beta$-catenin (BD Transduction Laboratories, USA), anti-cyclin D1 (Santa Cruz Biotechnology, USA), anti-c-myc (Santa Cruz Biotechnology), anti-poly(ADP) ribose polymerase (anti-PARP; Cell Signaling Technology, USA), anti-cleaved caspase-3 (Cell Signaling Technology), anti-phospho- $\beta$-catenin (Ser33/37/Thr41) (Cell Signaling Technology) and anti-actin (Cell Signaling Technology). The membranes were then incubated with horseradish peroxidaseconjugated anti-mouse IgG (Santa Cruz Biotechnology) or anti-rabbit IgG (Santa Cruz Biotechnology). The bands were visualized using the ECL system (Santa Cruz Biotechnology) and quantified using the ImageJ software (NIH, USA).

\section{RNA Isolation and Real-Time PCR}

Total RNA was isolated using Trizol reagent (Invitrogen) following the manufacturer's protocol. cDNA synthesis and PCR were performed as previously described [14]. The amplified DNA was separated using 2\% agarose gels and stained with LoadingStar (Dynebio, Korea). For real-time PCR, the CFX96 qPCR system (BioRad) was used. Reactions were carried out in 96-well optical reaction plates in a $20 \mu \mathrm{l}$ final volume containing $10 \mu \mathrm{l}$ of the 2X SsoFast EvaGreen Supermixes (Bio-Rad), $1 \mu$ of each gene-specific forward primer, $1 \mu$ l of each genespecific reverse primer, $1 \mu \mathrm{l}$ of diluted cDNA sample, and $7 \mu \mathrm{l}$ of water. After an initial denaturing step for $10 \mathrm{~min}$ at $95^{\circ} \mathrm{C}$, conditions for cycling were set to 40 cycles of $30 \mathrm{~s}$ at $94^{\circ} \mathrm{C}, 30 \mathrm{~s}$ at $58^{\circ} \mathrm{C}$, and $30 \mathrm{~s}$ at $72^{\circ} \mathrm{C}$. The changes in gene expression were quantified by the comparative $\mathrm{Ct}$ method by calculating the relative fold changes normalized against $\beta$-actin expression [16].

\section{Cell Viability Assays}

Cells were inoculated into 96-well plates and treated with either DMSO or MRBE ( 20 and $40 \mu \mathrm{g} / \mathrm{mL})$ and ursolic acid $(20$ and $40 \mu \mathrm{M})$. After $48 \mathrm{~h}$, the cell viability of each treated sample was measured in triplicate with the Celltiter-Glo Assay Kit (Promega) according to the manufacturer's instructions. To calculate the inhibition of cell growth, the value at time 0 was subtracted.

\section{Apoptosis Analysis}

After treatment with either DMSO or MRBE $(20$ and $40 \mu \mathrm{g} / \mathrm{ml})$ and ursolic acid $(20$ and $40 \mu \mathrm{M})$ for $48 \mathrm{~h}$, cells were washed with cold phosphate-buffered saline and stained with annexin V-FITC and PI. The levels of apoptosis were then measured using the Apoptosis Detection Kit (BD Transduction Laboratories), according to the manufacturer's protocols. Cells were then analyzed using a Cellometer cytometer (Nexcelom, USA).

\section{Metabolite Profiling by UPLC-Orbitrap MS}

M. alba L. root bark metabolites were extracted as described previously $[17,18]$. An Ultimate-3000 UPLC system (Thermo Fisher Scientific, USA) coupled with a Q-Exactive Focus Hybrid Quadrupole-Orbitrap Mass Spectrometer Plus instrument (Thermo Fisher Scientific) was used to perform the LC-MS/MS analysis. The metabolite separation from MRBE $(20 \mathrm{mg})$ was conducted on a UPLC BEH C18 $1.7 \mu \mathrm{m} 2.1 \times 150 \mathrm{~mm}$ column (Waters, USA) equipped with UPLC BEH C18 $1.7 \mu \mathrm{m} 2.1 \times 5.0 \mathrm{~mm}$ VanGuard Pre-Column (Waters). The mobile phase consisted of $0.1 \%$ formic acid in water (buffer A) and $0.1 \%$ formic acid in acetonitrile (buffer B). The chromatographic separation was programmed as follows (buffer B): 0-2.0 min, 5\%; 2.0-25.0 min, 5-95\%; 25.0 $27.5 \mathrm{~min}, 95 \%$; and $27.6-30.0 \mathrm{~min}, 5 \%$. The flow rate was set to $300 \mu \mathrm{L} / \mathrm{min}$. The mass spectra data were acquired using Full MS-ddMS2 (top3) scan mode in positive ionization mode. Data acquisition and processing were performed using the Xcalibur software (Thermo Fisher Scientific).

\section{Caspase 3/7 Assay}

The activity of caspase-3/7 was determined in cell lysates using the Apo-ONE Homogeneous Caspase-3/7 Assay Kit (Promega). 


\section{Statistical Analysis}

Student's $t$-tests were employed to compare the means of the control and experimental groups. All experiments were conducted three times. Statistical significance was set to $p<0.05\left(^{*}\right)$ or $p<0.01\left(^{* *}\right)$. The results were expressed as mean \pm standard deviation (SD).

\section{Results}

MRBE Inhibits the Wnt/ $\beta$-Catenin Pathway by Promoting GSK-3 $\beta$-Independent $\beta$-Catenin Degradation

To elucidate the mechanisms underlying the MRBE anticancer activity, we used HEK293-firefly luciferase (FL) reporter cells stably harboring a synthetic $\beta$-catenin/TCF-dependent FL reporter (TOPFlash) and an hFz-1 expression plasmid. The incubation of HEK293-FL reporter cells with Wnt3a-conditioned medium (Wnt3a-CM) increased CRT activity. However, MRBE addition led to a concentration-dependent decrease in CRT (Fig. 1A).

A

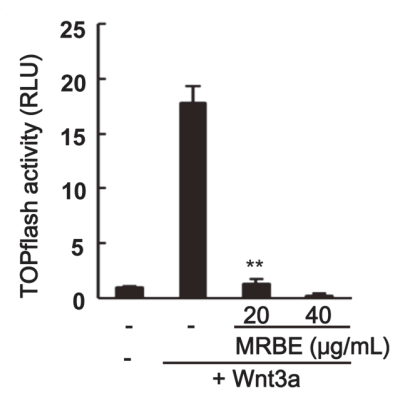

C

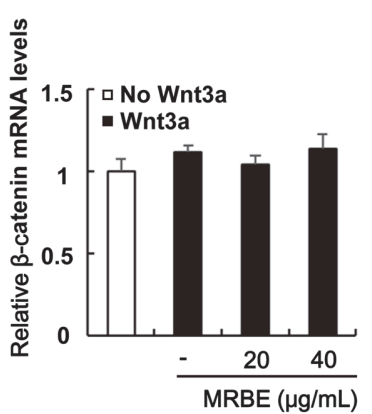

E

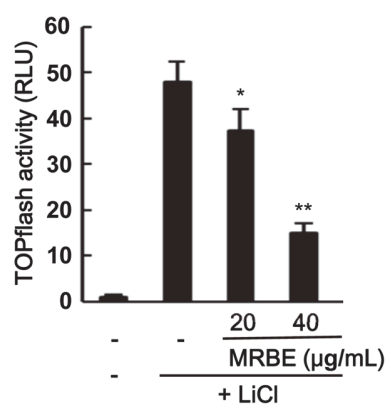

B MRBE

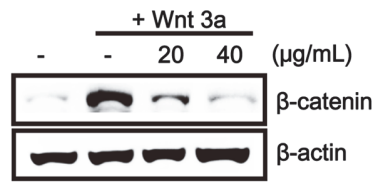

D

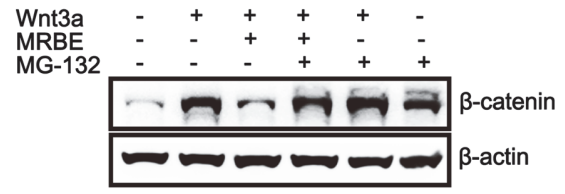

$\mathrm{F}$

MRBE

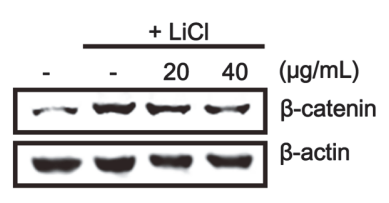

Fig. 1. Identification of Morus alba L. root bark extract (MRBE) as an inhibitor of the Wnt/ $\beta$-catenin pathway. (A) Firefly luciferase (FL) activity determined in HEK293-FL reporter cells incubated with either DMSO (vehicle) or MRBE $(20$ and $40 \mu \mathrm{g} / \mathrm{ml})$ in the presence of Wnt3a-CM for $15 \mathrm{~h}$. (B) Downregulation of $\beta$-catenin protein levels by MRBE in the presence of Wnt3a-CM. (C) Effect of MRBE on $\beta$-catenin mRNA levels. Real-time PCRs for the analysis of $\beta$-catenin and GAPDH were performed with total RNA prepared from HEK293-FL reporter cells treated with either DMSO or the indicated concentrations of MRBE, in the presence of Wnt3a-CM, for $15 \mathrm{~h}$. (D) Western blot with the anti- $\beta$-catenin antibody on cytosolic proteins prepared from HEK293-FL reporter cells exposed to MRBE $(20 \mu \mathrm{g} / \mathrm{ml})$ for $15 \mathrm{~h}$ and MG-132 (10 $\mu \mathrm{M})$ for $8 \mathrm{~h}$. (E) Luciferase assay of HEK293 reporter cells incubated with MRBE in the presence of $20 \mathrm{mM} \mathrm{LiCl}$ for $15 \mathrm{~h}$. (F) Western blot with the $\beta$-catenin antibody on cytosolic proteins from HEK293 reporter cells treated with DMSO or increasing amounts of MRBE in the presence of $40 \mathrm{mM} \mathrm{LiCl}$ for $15 \mathrm{~h}$. The results represent the mean $\pm \mathrm{SD}$ of three independent experiments. ${ }^{*} p<0.05$ and ${ }^{* *} p<0.01$, cells treated with either Wnt3a-CM or LiCl compared with cells treated with MRBE. 
We then employed western blot analysis to test the effects of MRBE on intracellular levels of $\beta$-catenin, a principal regulator of CRT in the Wnt/ $\beta$-catenin pathway. As shown in Fig. 1B, MRBE reduced the cytoplasmic $\beta$-catenin protein levels accumulated by Wnt3a-CM in HEK293-FL reporter cells. Under these conditions, $\beta$-catenin mRNA levels were not altered by MRBE (Fig. 1C). $\beta$-Catenin is targeted by a proteasome-dependent degradation pathway [19]; hence, we used the proteasome inhibitor MG-132 to examine the involvement of the proteasome in $\beta$ catenin downregulation by MRBE. As depicted in Fig. 1D, the treatment of HEK293-FL reporter cells with MRBE consistently decreased intracellular $\beta$-catenin levels, but the addition of MG-132 abolished this effect. Taken together, these data indicate that MRBE suppresses the Wnt/ $\beta$-catenin pathway by inducing proteasomedependent $\beta$-catenin degradation.

Glycogen synthase kinase-3 $\beta$ (GSK-3 $\beta$ )-mediated $\beta$-catenin phosphorylation at Ser33/37/Thr41 is central in the proteasome-dependent $\beta$-catenin degradation pathway [20]. Therefore, we examined whether GSK-3 $\beta$ activity is required for MRBE-induced $\beta$-catenin degradation. As shown in Fig. 1E, the treatment of HEK293-FL reporter cells with MRBE still led to a dose-dependent decrease in CRT in the presence of $\mathrm{LiCl}$, which is a GSK-3 $\beta$ inhibitor that increases CRT [21]. Moreover, western blot analysis using an anti- $\beta$-catenin antibody showed that MRBE treatments reduced the intracellular $\beta$-catenin levels increased by LiCl (Fig. 1F). Next, we examined whether MRBE induces the Ser33/37/Thr41 phosphorylation of $\beta$-catenin by western blot analysis with a phospho-specific $\beta$-catenin antibody, In the presence of $\mathrm{LiCl}$, the $\beta$-catenin phosphorylation levels at Ser33/37/ Thr41 residues were decreased but were increased with the addition of MRBE (Fig. S1). Taken together, these results suggest that MRBE can suppress the Wnt/ $\beta$-catenin pathway partly by inducing GSK-3 $\beta$-independent $\beta$ catenin degradation.

MRBE Inhibits MM Cell Proliferation by Downregulating $\beta$-Catenin Levels

A previous study demonstrated that $\beta$-catenin is constitutively upregulated in RPMI-8226 and MM.1S MM cells [22]. We investigated the effect of MRBE treatments on $\beta$-catenin levels in RPMI-8226 cells through western blot analysis with an anti- $\beta$-catenin antibody. As presented in Fig. 2A, MRBE decreased intracellular $\beta$-catenin levels in RPMI-8226 cells. We then examined the effect of different MRBE concentrations on the expression of $\beta$ catenin target genes in RPMI-8226 cells through western blot analysis. MRBE caused a dose-dependent downregulation of the well-characterized $\beta$-catenin-dependent genes, c-myc and cyclin D1 (Fig. 2B). Because the disruption of $\beta$-catenin function can inhibit the proliferation of MM cells [23], we assessed the effect of MRBE on

A

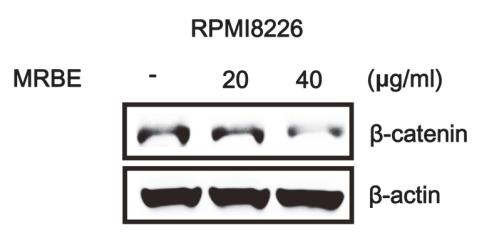

B

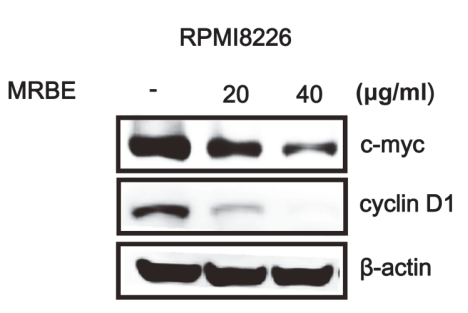



C


MM1S



Fig. 2. MRBE inhibits the expression of $\beta$-catenin and its dependent genes in RPMI8226. (A) Effect of MRBE on $\beta$-catenin protein levels in RPMI8226 cells. (B) Western blot with anti-c-myc, anti-cyclin D1, and anti- $\beta$-actin (loading control) antibodies on extracts of RPMI-8226 cells incubated with either DMSO (vehicle) or MRBE (20 and $40 \mu \mathrm{g} / \mathrm{ml})$ for $15 \mathrm{~h}$. (C) Cell viability of RPMI-8226 cells and MM.1S. Cells were incubated for $48 \mathrm{~h}$ in 96 -well plates. To calculate the inhibition of cell growth, the value at time 0 was subtracted. The results represent the mean $\pm S D$ of three independent experiments. ${ }^{*} p<0.05$ and ${ }^{*} p<0.01$, compared with the DMSO control. 
A

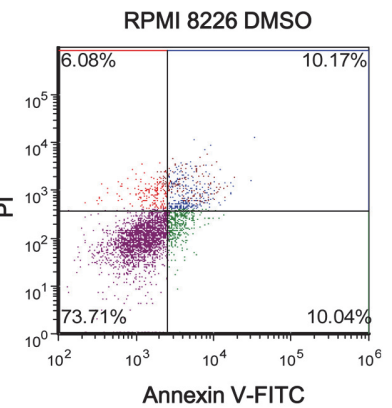

B



RPMI8226 MRBE $20 \mu \mathrm{g} / \mathrm{ml}$
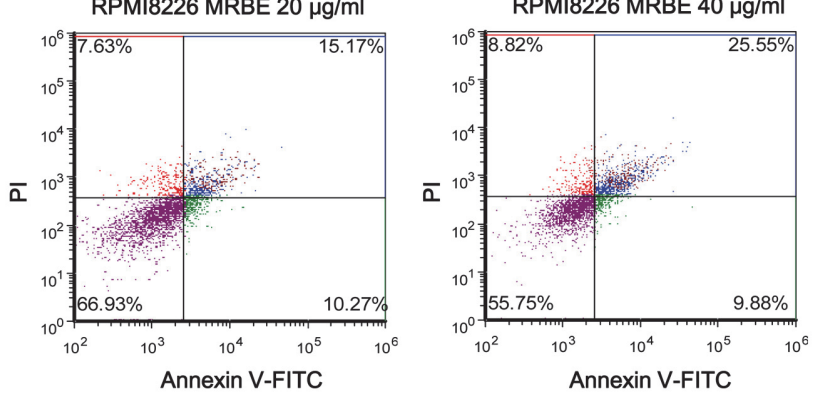

C

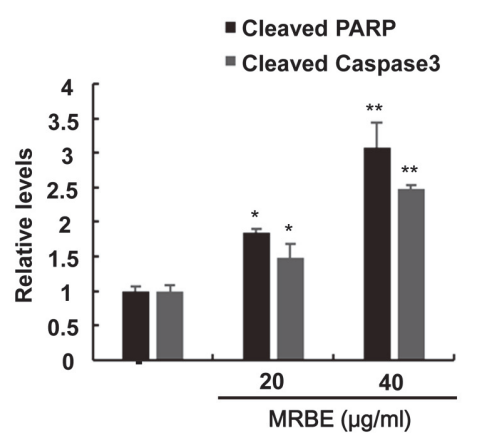

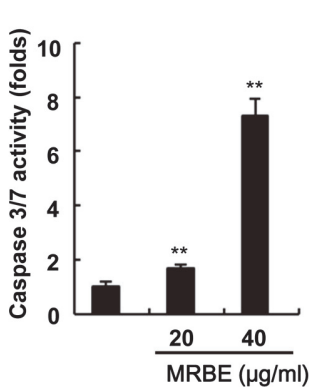

Fig. 3. Apoptotic effects of MRBE on RPMI-8226 cell growth. (A) Cytometry analysis of RPMI-8226 cells incubated with either DMSO (vehicle) or MRBE (20 and $40 \mu \mathrm{g} / \mathrm{ml}$ ) for $48 \mathrm{~h}$. After incubation, cells were harvested and stained with annexin V-FITC and propidium iodide (PI). The $x$-axis indicates the annexin V-FITC intensity, while the $y$-axis indicates the PI fluorescence. (B) Western blot with anti-caspase-3, anti-poly (ADP-ribose) polymerase (PARP), and anti-actin (loading control) antibodies on whole-cell extracts. The results are representative of three independent experiments. (C) Caspase-3/7 activity determined after RPMI8226 cell incubation with either DMSO or MRBE (20 and $40 \mu \mathrm{g} / \mathrm{ml})$ for $48 \mathrm{~h}$. The results represent the mean $\pm \mathrm{SD}$ of three independent experiments. ${ }^{*} p<0.05$ and ${ }^{\star *} p<0.01$ compared with the DMSO control group.

the growth of MM cells. As depicted in Fig. 2C, MRBE efficiently inhibited the proliferation of RPMI-8226 and MM.1S cells in a concentration-dependent manner. These results suggest that MRBE suppresses the proliferation of MM cells by downregulating $\beta$-catenin levels.

\section{MRBE Induces Apoptosis in RPMI-8226 MM Cells}

To elucidate the antiproliferative mechanisms triggered by MRBE, we exposed RPMI-8226 cells to MRBE and determined the number of annexin V-FITC/propidium iodide-stained apoptotic cells using a cytometer. As presented in Fig. 3A, the population of apoptotic cells (annexinV-FITC/propidium iodide (PI) double-positive cells) increased in a dose-dependent manner. Western blot analysis showed that MRBE treatments led to the formation of active caspase-3 (cleaved form), which in turn catalyzed the cleavage of anti-poly (ADP-ribose) polymerase (PARP), a biochemical apoptosis marker (Fig. 3B). Consistently, the activity of caspase-3/7 increased in response to MRBE treatments (Fig. $3 \mathrm{C}$ ). These results indicate that apoptosis contributes to the MRBE-induced RPMI-8226 cell growth inhibition.

\section{Identification of Ursolic Acid from MRBE through LC/Mass Spectrum (MS) Analysis}

Secondary metabolites have been identified in the root bark of $M$. alba L., including terpenoids, flavonoids, and stilenoids [24]. To comprehensively profile the metabolite contents in the root bark extract (MRBE), we performed UPLC-Orbitrap MS analysis in an untargeted manner. A total of 121 metabolites were structurally identified and classified as amino acids, isoflavones, and isoflavonoids (Table S1). Among metabolites, ursolic acid is a pentacyclic terpenoid with a wide range of pharmaceutical properties found in the root bark of M. alba L. $[24,25]$. The terpenoid has previously been demonstrated to inhibit the Wnt/ $\beta$-catenin pathway and suppress the proliferation of adenomatous polyposis coli (APC)-mutated colon cancer, osteosarcoma, and PC-3 prostate cancer cells [26-28]. Accordingly, we determined ursolic acid in MRBE. The comparative analysis using the authentic compound of ursolic acid confirmed the base peak at $457.3674 \mathrm{~m} / \mathrm{z}(25 \mathrm{~min})$ as $[\mathrm{M}+\mathrm{H}]^{+}$ions (Fig. 4A). Furthermore, the tandem MS/MS spectrum of the ion matched the fragmentation pattern of the reference compound (Figs. 4B, C). Based on one-point calibration, the ursolic acid content was estimated as $28.96 \mu \mathrm{g}$ in $20 \mathrm{mg}$ of MRBE. 

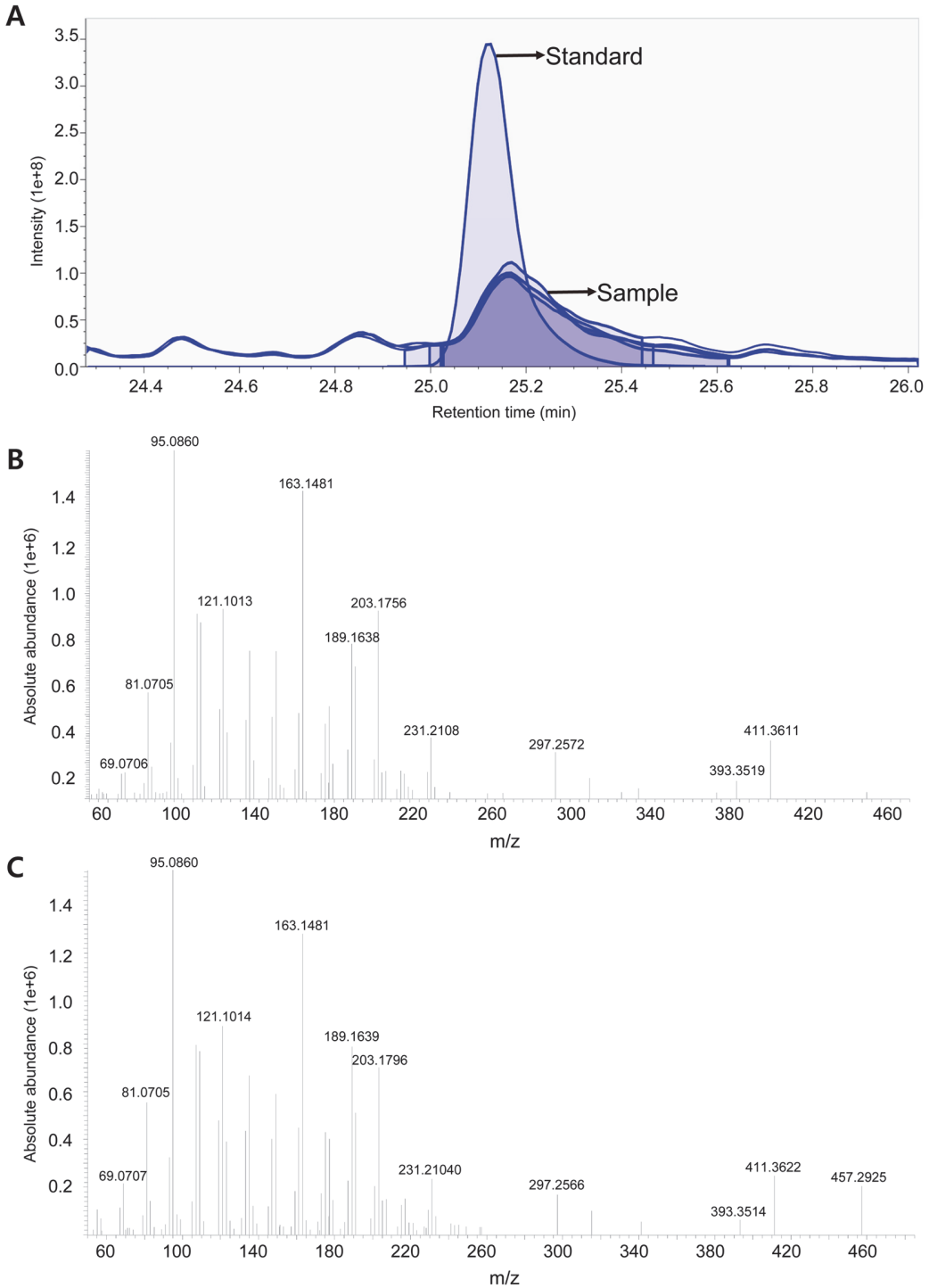

Fig. 4. LC-MS analysis of ursolic acid in MRBE. (A) Extracted ion chromatogram of ursolic acid in standard solution and MRBE. The tandem mass spectra of ursolic acid in standard solution (B) and MRBE (C).

\section{Ursolic Acid Downregulates $\beta$-Catenin and Represses Its Target Genes in MM Cells}

We then explored the effect of ursolic acid on MM. The incubation of RPMI-8226 and MM.1S cells with ursolic acid resulted in the downregulation of cytoplasmic $\beta$-catenin expression (Figs. 5A, S2). The effect of ursolic acid on the expression of $\beta$-catenin-dependent genes in RPMI- 8226 cells was then evaluated. After treatment of RPMI8226 cells with various amounts of ursolic acid, the expression levels of c-myc and cyclin D1 were measured using western blot analysis. As expected, we found a significant downregulation in c-myc and cyclin D1 protein levels (Fig. 5B). Consistent with the results from MRBE, ursolic acid efficiently suppressed the growth of RPMI-8226 and MM.1S cells (Fig. 5C). These results indicate that ursolic acid may be an active ingredient responsible for the MRBE-mediated inhibition of the Wnt/ $\beta$-catenin pathway and MRBE-induced growth suppression in MM cells.

\section{Ursolic Acid Induces Cell Cycle Arrest and Apoptosis in RPMI-8226 MM Cells}

To investigate the possible mechanism for ursolic acid-mediated growth inhibition in MM cells, RPMI-8226 cells were treated with ursolic acid and the distribution of the cell cycle was examined after cell staining with propidium iodide (PI). As shown in Fig. S2, cytometric analysis demonstrated that the populations of RPMI-8226 in $\mathrm{G} 2 / \mathrm{M}$ phase were elevated from 36.4 to $52.4 \%$, compared with the vehicle control. We also analyzed the ability of ursolic acid to induce apoptosis in RPMI-8226 cells. Annexin V-FITC/PI staining showed that the percentage of apoptotic cells increased following ursolic acid treatment (Fig. 6B). In addition, incubating RPMI-8226 cells with ursolic acid stimulated the formation of cleaved caspase-3 and PARP forms (Fig. 6C) and increased caspase-3/7 activity (Fig. 6D). These results suggest that both cell cycle arrest at G2/M phase and apoptosis contributed to the ursolic acid-induced inhibition of MM cell proliferation. 
A

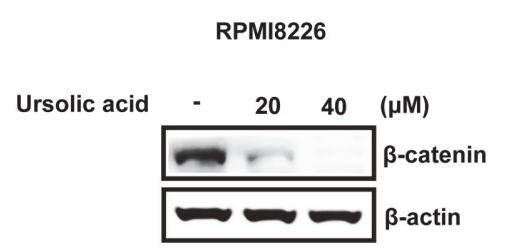

B

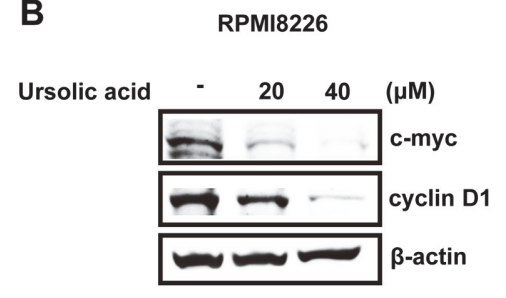

C
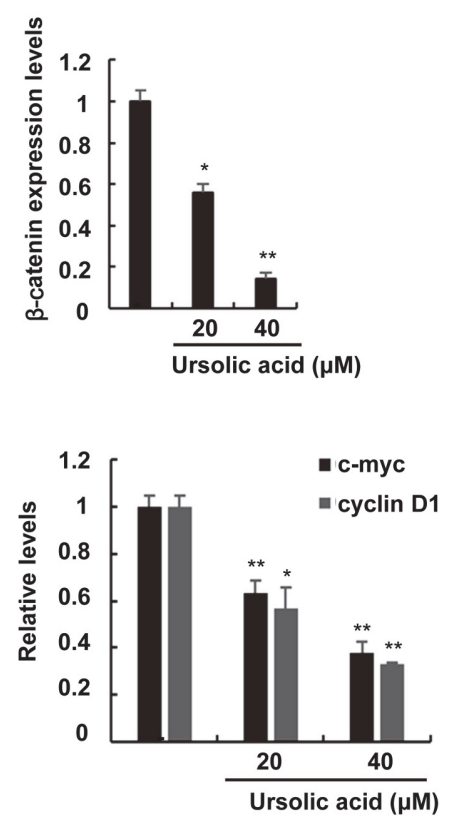

RPMI8226

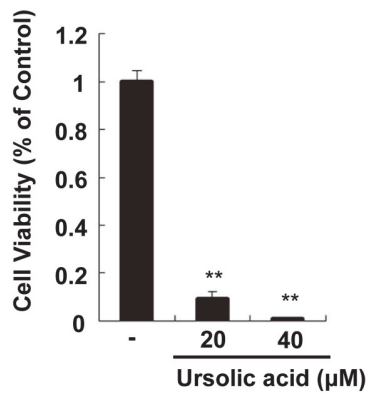

MM.1S



Fig. 5. Ursolic acid inhibits the expression of $\beta$-catenin and its dependent genes in RPMI8226. (A) Effect of ursolic acid on $\beta$-catenin protein levels in RPMI8226 cells. (B) Western blot with anti-c-myc, anti-cyclin D1, and anti- $\beta$-actin (loading control) antibodies on extracts of RPMI-8226 cells incubated with the DMSO (vehicle) or ursolic acid (20 and $40 \mu \mathrm{M}$ ) for $15 \mathrm{~h}$. (C) Cell viability of RPMI-8226 cells with the given concentrations of ursolic acid. RPMI-8226 cells were incubated for $48 \mathrm{~h}$ in 96 -well plates. To calculate the inhibition of cell growth, the value at time 0 was subtracted. The results represent the mean \pm SD of three independent experiments. ${ }^{*} p<0.05$ and ${ }^{* *} p<0.01$, compared with the DMSO control group.

\section{Discussion}

Medicinal plants are potential resources for developing therapeutics targeting human diseases. The root bark of M. alba L., a traditional Chinese medicine, produces various natural compounds, including terpenoids, flavonoids, and stilenoids [24]. Interestingly, a recent study reported that MRBE has cytotoxic effects on non-small-cell lung cancer cells $[11,12]$. However, the underlying antiproliferative mechanisms and the active metabolites associated remain unknown. In this study, we demonstrated that MRBE and its active ingredient, ursolic acid, are bona fide cancer antagonists as evidenced by their effect in downregulating CRT and cytoplasmic $\beta$-catenin levels.

The Wnt/ $\beta$-catenin pathway plays a significant role in regulating cell proliferation, differentiation, and development [29-31]. Central to this pathway is the regulation of intracellular $\beta$-catenin levels. They are controlled by GSK-3 $\beta$-mediated phosphorylation at Ser33/37/Thr41 in the $\beta$-catenin destruction complex, composed of APC, Axin, casein kinase 1, and GSK-3 $\beta$ [30]. Phosphorylated $\beta$-catenin is recognized by the $\beta$ transducin repeat-containing protein, an F-box E3 ubiquitin ligase, and degraded through a proteasomaldependent pathway $[31,32]$. It is noteworthy that MRBE still promoted $\beta$-catenin degradation in the presence of $\mathrm{LiCl}$, a GSK-3 $\beta$ inhibitor, indicating that GSK-3 $\beta$ is not required for MRBE-induced $\beta$-catenin degradation. Previous studies reported that cyclin-dependent kinase $2 /$ cyclin A or cyclin E and protein kinase Ca are also involved in $\beta$-catenin degradation $[33,34]$. Thus, the activity of these kinases may be necessary for MRBEmediated $\beta$-catenin degradation. Recently, ursolic acid has been shown to decrease the $\beta$-catenin levels by increasing the level of Wnt antagonists, sFRP4 and DKK1, in breast cancer stem-like cells [35].

Constitutive upregulation of the Wnt/ $\beta$-catenin pathway frequently occurs in MM without the presence of mutations in this pathway [4]. In addition, the stimulation of the Wnt/ $\beta$-catenin pathway by Wnt3a and $\mathrm{LiCl}$ significantly increases the proliferation of MM cells [36]. Therefore, suppressing this pathway might be an effective strategy for MM treatment. The small molecule PKF115-585 inhibits MM cell proliferation by disrupting the interaction of the transcriptionally active $\beta$-catenin/TCF complex [37]. Recently, ICG-001, which can inhibit the formation of the transcriptional coactivator $\mathrm{CBP} / \beta$-catenin complex, was shown to selectively promote apoptosis in primary MM cells [38]. In this study, we demonstrated, for the first time, that MRBE and its constituent, ursolic acid, induces cell cycle arrest and apoptosis by suppressing the Wnt/ $\beta$-catenin pathway in multiple myeloma cells.

Based on one-point estimation with the standard compound, the molar concentration of ursolic acid in $40 \mu \mathrm{g} /$ mL MRBE was $0.13 \mu \mathrm{M}$, which is lower than the minimal effective concentration on MM cell growth inhibition (Fig. S3). Several studies have reported that natural compounds isolated from MRBE inhibit the proliferation of MM cells. Betulinic acid induces apoptotsis and cell cycle arrest by inhibiting NF-kB pathway in multiple myeloma [39]. In addition, $\beta$-sitosterol promotes apoptosis through activating AMP-activated protein kinase 
A



B



C

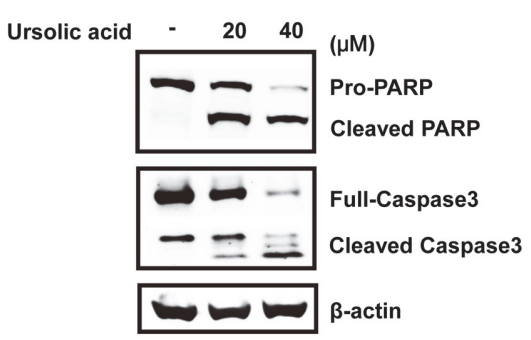

RPMI8226 Ursolic acid 20 $\mu \mathrm{M}$

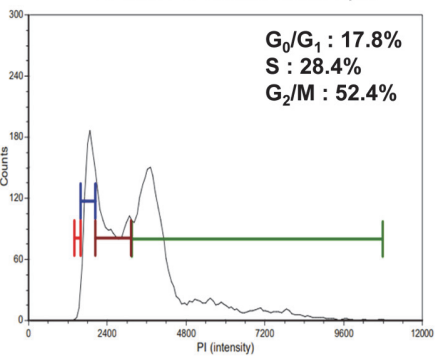

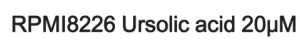

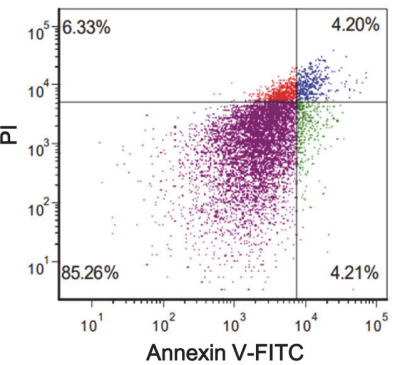

- Cleaved PARP

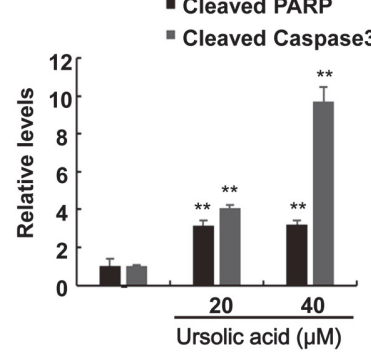

RPMI8226 Ursolic acid 40 $\mu \mathrm{M}$



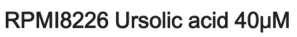

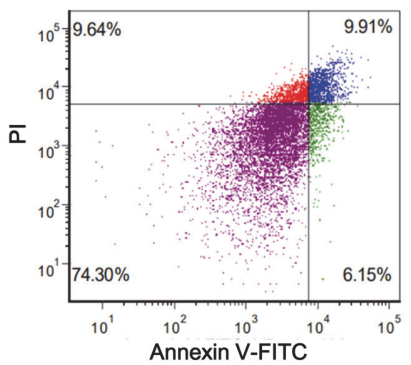

D

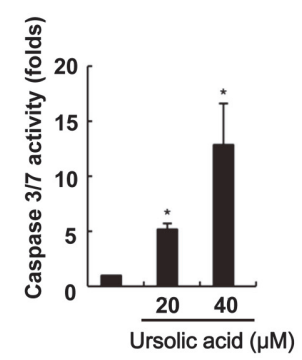

Fig. 6. Apoptotic effects of ursolic acid on RPMI-8226 cell growth. (A) RPMI-8226 cells were incubated with the DMSO (vehicle) or ursolic acid $(20$ and $40 \mu \mathrm{M})$ for $48 \mathrm{~h}$. After incubation, cells were harvested and stained with propidium iodide (PI) and analyzed using a cytometer. The $x$-axis indicates the PI fluorescence intensity that correlated with the DNA content. (B) RPMI-8226 cells were incubated with the DMSO (vehicle) or ursolic acid (20 and $40 \mu \mathrm{M})$ for $48 \mathrm{~h}$. After incubation, cells were harvested and stained with annexin V-FITC and PI and analyzed using a cytometer. The $x$-axis indicates the annexin V-FITC intensity, while the $y$-axis indicates the PI fluorescence. (C) Western blot with anti-caspase-3, anti-poly (ADP-ribose) polymerase (PARP), and anti-actin (loading control) antibodies on whole-cell extracts. The results are representative of three independent experiments. (D) Caspase-3/7 activity determined after RPMI8226 cell incubation with either DMSO (vehicle) or ursolic acid $(20$ and $40 \mu \mathrm{M})$ for $48 \mathrm{~h}$. The results represent the mean \pm SD of three independent experiments. ${ }^{*} p<0.05$ compared with the DMSO control group.

(AMPK) and c-Jun N-terminal kinase (JNK) [39]. In this context, though the estimated concentration of ursolic acid in MRBE may not be sufficient for MRBE-mediated suppression of MM cell proliferation, ursolic acid in MRBE, in a synergy with betulinic acid and/or $\beta$-sitosterol, can inhibit the growth of MM cells.

In conclusion, this is the first study to identify the antiproliferative potency of MRBE and ursolic acid against MM cells and reveal the molecular mechanism. MRBE and ursolic acid accelerate oncogenic $\beta$-catenin turnover and repress $\beta$-catenin-dependent gene expression, thereby suppressing MM cell growth through apoptosis. Therefore, MRBE and ursolic acid have potential to be developed into preventive or therapeutic agents for MM treatment.

\section{Acknowledgments}

This work was supported by a Korea Environmental Industry and Technology Institute (KEITI) grant funded by the Ministry of Environment of Korea and by a research fund of Chungnam National University.

\section{Conflict of Interest}

The authors have no financial conflicts of interest to declare. 


\section{References}

1. Group IMW. 2003. Criteria for the classification of monoclonal gammopathies, multiple myeloma and related disorders: a report of the International Myeloma Working Group. Br. J. Haematol. 121: 749-757.

2. Sukhdeo K, Mani M, Zhang Y, Dutta J, Yasui H, Rooney MD, et al. 2007.Targeting the $\beta$-catenin/TCF transcriptional complex in the treatment of multiple myeloma. Proc. Natl. Acad. Sci. USA 104: 7516-7521.

3. Latres E, Chiaur D, Pagano M. 1999. The human F box protein $\beta$-Trcp associates with the Cull/Skp1 complex and regulates the stability of $\beta$-catenin. Oncogene 18: 849-854.

4. Derksen PW, Tjin E, Meijer HP, Klok MD, Mac Gillavry HD, van Oers MH, et al. 2004. Illegitimate WNT signaling promotes proliferation of multiple myeloma cells. Proc. Natl. Acad. Sci. USA 101: 6122-6127.

5. He T-C, Sparks AB, Rago C, Hermeking H, Zawel L, Da Costa LT, et al. 1998. Identification of c-MYC as a target of the APC pathway. Science 281: 1509-1512.

6. He T-C, Chan TA, Vogelstein B, Kinzler KW. 1999. PPAR $\delta$ is an APC-regulated target of nonsteroidal anti-inflammatory drugs. Cell 99: 335-345.

7. Tetsu O, McCormick F. 1999. $\beta$-Catenin regulates expression of cyclin D1 in colon carcinoma cells. Nature 398: 422-426.

8. Takahashi M, Tsunoda T, Seiki M, Nakamura Y, Furukawa Y. 2002. Identification of membrane-type matrix metalloproteinase-1 as a target of the $\beta$-catenin/Tcf4 complex in human colorectal cancers. Oncogene 21: 5861-5867.

9. Eo HJ, Park JH, Park GH, Lee MH, Lee JR, Koo JS, et al. 2014. Anti-inflammatory and anti-cancer activity of mulberry (Morus alba L.) root bark. BMC Complement. Altern. Med. 14: 1200

10. Nam S-Y, Yi H-K, Lee JC, Kim JC, Song CH, Park JW, et al. 2002. Cortex mori extract induces cancer cell apoptosis through inhibition of microtubule assembly. Arch. Pharm. Res. 25: 191-196.

11. Park S-H, Chi GY, Eom HS, Kim G-Y, Hyun JW, Kim W-J, et al. 2012. Role of autophagy in apoptosis induction by methylene chloride extracts of Mori cortex in NCI-H460 human lung carcinoma cells. Int. J. Oncol. 40: 1929-1940.

12. Min T-R, Park H-J, Park MN, Kim B, Park S-H. 2019. The root bark of Morus alba L. suppressed the migration of human non-smallcell lung cancer cells through inhibition of epithelial-mesenchymal transition mediated by STAT3 and Src. Int. J. Mol. Sci. $20: 2244$.

13. Shen M, Hu Y, Yang Y, Wang L, Yang X, Wang B, et al. 2019. Betulinic acid induces ROS-dependent apoptosis and S-phase arrest by

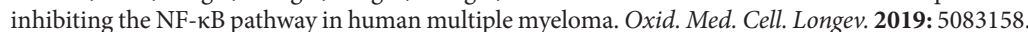

14. Ryu M-J, Cho M, Song J-Y, Yun Y-S, Choi I-W, Kim D-E, et al. 2008. Natural derivatives of curcumin attenuate the Wnt/ $\beta$-catenin pathway through down-regulation of the transcriptional coactivator p300. Biochem. Biophys. Res. Commun. 377: 1304-1308.

15. Dignam JD, Lebovitz RM, Roeder RG. 1983. Accurate transcription initiation by RNA polymerase II in a soluble extract from isolated mammalian nuclei. Nucleic Acids Res. 11: 1475-1489.

16. Park S, Lee M-S, Gwak J, Choi T-I, Lee Y, Ju BG, et al. 2018. CCAAT/enhancer-binding protein- $\beta$ functions as a negative regulator of Wnt/ $\beta$-catenin signaling through activation of AXIN1 gene expression. Cell Death Dis. 9: 1023.

17. Lee DY, Fiehn O. 2008. High quality metabolomic data for Chlamydomonas reinhardtii. Plant Methods. 4: 7

18. Son Y, Lee EM, Lee DY, Lee JH, Oh S. 2019. Longan fruit increase bone mineral density in zebrafish and ovariectomized rat by suppressing RANKL-induced osteoclast differentiation. Phytomedicine 59: 152910.

19. He X, Semenov M, Tamai K, Zeng X. 2004. LDL receptor-related proteins 5 and 6 in Wnt/ $\beta$-catenin signaling: arrows point the way. Development 131: 1663-1677.

20. Liu C, Li Y, Semenov M, Han C, Baeg G-H, Tan Y, et al. 2002. Control of $\beta$-catenin phosphorylation/degradation by a dual-kinase mechanism. Cell 108: 837-847.

21. Klein PS, Melton DA. 1996. A molecular mechanism for the effect of lithium on development. Proc. Natl. Acad. Sci. USA 93: 84558459 .

22. Chapman MA, Lawrence MS, Keats JJ, Cibulskis K, Sougnez C, Schinzel AC, et al. 2011. Initial genome sequencing and analysis of multiple myeloma. Nature 471: 467-472.

23. Schmeel LC, Schmeel FC, Kim Y, Endo T, Lu D, Schmidt-Wolf IG. 2013. Targeting the Wnt/beta-catenin pathway in multiple myeloma. Anticancer Res. 33: 4719-4726.

24. Chan EW-C, Phui-Yan L, Siu-Kuin W. 2016. Phytochemistry, pharmacology, and clinical trials of Morus alba. Chin. J. Nat. Med. 14: $17-30$.

25. Woźniak Ł, Skąpska S, Marszałek K. 2015. Ursolic acid-a pentacyclic triterpenoid with a wide spectrum of pharmacological activities. Molecules 20: 20614-20641.

26. Kim J-H, Kim YH, Song G-Y, Kim D-E, Jeong Y-J, Liu K-H, et al. 2014. Ursolic acid and its natural derivative corosolic acid suppress the proliferation of APC-mutated colon cancer cells through promotion of $\beta$-catenin degradation. Food Chem. Toxicol. 67: 87-95.

27. Zhang RX, Li Y, Tian DD, Liu Y, Nian W, Zou X, et al. 2016. Ursolic acid inhibits proliferation and induces apoptosis by inactivating Wnt/ $\beta$-catenin signaling in human osteosarcoma cells. Int. J. Oncol. 49: 1973-1982.

28. Park J-H, Kwon H-Y, Sohn EJ, Kim KA, Kim B, Jeong S-J, et al. 2013. Inhibition of Wnt/ $\beta$-catenin signaling mediates ursolic acidinduced apoptosis in PC-3 prostate cancer cells. Pharmacol. Rep. 65: 1366-1374.

29. Wodarz A, Nusse R. 1998. Mechanisms of Wnt signaling in development. Ann. Rev. Cell Dev. Biol. 14: 59-88.

30. Aberle H, Bauer A, Stappert J, Kispert A, Kemler R. 1997. $\beta$-catenin is a target for the ubiquitin-proteasome pathway. EMBO J. 16: $3797-3804$

31. Miller JR. The Wnts. 2001. Genome Biol. 3: Reviews3001.

32. Hart M, Concordet J, Lassot I, Albert I, Del los Santos R, Durand H, et al. 1999. The F-box protein $\beta$-TrCP associates with phosphorylated $\beta$-catenin and regulates its activity in the cell. Curr. Biol. 9: 207-211.

33. Gwak J, Cho M, Gong S-J, Won J, Kim D-E, Kim E-Y, et al. 2006. Protein-kinase-C-mediated $\beta$-catenin phosphorylation negatively regulates the Wnt/B-catenin pathway. J. Cell Sci. 119:4702-4709.

34. Gwak J, Jung SJ, Kang DI, Kim EY, Kim DE, Chung YH, et al. 2009. Stimulation of protein kinase Ca suppresses colon cancer cell proliferation by down-regulation of $\beta$-catenin. J. Cell. Mol. Med. 13: 2171-2180.

35. Mandal S, Gamit N, Varier L, Dharmarajan A, Warrier S. 2021. Inhibition of breast cancer stem-like cells by a triterpenoid, ursolic acid, via activation of Wnt antagonist, sFRP4 and suppression of miRNA-499a-5p. Life Sci. 265: 118854.

36. Spaan I, Raymakers RA, van de Stolpe A, Peperzak V. 2018. Wnt signaling in multiple myeloma: a central player in disease with therapeutic potential. J. Hematol. Ocol. 11: 67.

37. Park S, Yun E, Hwang IH, Yoon S, Kim D-E, Kim IS, et al. 2014. Ilimaquinone and ethylsmenoquinone, marine sponge metabolites, suppress the proliferation of multiple myeloma cells by down-regulating the level of $\beta$-catenin. Mar. Drugs 12: 3231-3244.

38. Grigson ER, Ozerova M, Pisklakova A, Liu H, Sullivan DM, Nefedova Y. 2015. Canonical Wnt pathway inhibitor ICG-001 induces cytotoxicity of multiple myeloma cells in Wnt-independent manner. PLoS One 10: e0117693.

39. Sook SH, Lee HJ, Kim JH, Sohn EJ, Jung JH, Kim B, et al. 2014. Reactive oxygen species-mediated activation of AMP-activated protein kinase and c-Jun N-terminal kinase plays a critical role in beta-sitosterol-induced apoptosis in multiple myeloma U266 cells. Phytother. Res. 28: 387-394. 